ANUARIo DE Estudios MEdiEvales (AEM)

36/1, enero-junio de 2006

pp. 355-384

ISSN 0066-5061

\title{
EL RETAULE DE SANTA MAGDALENA DE LES TRAGINES
}

\author{
Ma CARMEN RIU DE MARTín \\ Secretaria de «Índice Histórico Español»
}

Resum: Treball sobre dues peces d'un retaule trobat a l'església rural de Santa Magdalena de les Tragines en el municipi de Guixers, que en l'actualitat es conserven al Museu de la Vall de Lord (Sant Llorenç de Morunys). Es tracta de dues taules anònimes corresponents a l'estil Gòtic Internacional de final del segle XV i principi del segle XVI que mostren una clara influencia temàtica i estilística dels artistes de la Catalunya Nord.

Paraules clau: retaule; iconografía; estil; fonts; temàtica de martiris.

\begin{abstract}
This work studies two pieces of a altarpiece situated in the rural church called Santa Magdalena de les Tragines, which belongs to Guixers town; now these pieces are custodied in Museu de la Vall de Lord (Sant Llorenç de Morunys). Although nobody could find these tables author, whose style is named International Gothic, which was developed during the last period of fifteenth century and the first period of the sixteenth. Their style and tendency shows a clear influence from the North-Catalonian artists.
\end{abstract}

Keywords: altarpiece; iconography; style; sources; martyrdom subject.

\section{SUMARI}

1. Descripció i característiques del retaule.- 2. Anàlisi de les fonts consultades.- 3. L'Escola de Lleida.- 4. Altres assumptes relacionats amb martiris i actituds de fe.- 5. La representació de Santa Magdalena, Sant Lleïr i Sant Llop.- 6. Conclusions.

Al Museu de la Vall de Lord (Sant Llorenç de Morunys) s'hi troben dues taules sobre fusta, que caldria restaurar degut a l'estat en el qual es conserven i que procedeixen d'una església rural anomenada Santa Magdalena de les Tragines, annexada a una masia que se la coneix amb el nom de "Les Tragines". Es tracta de dos fragments o escenes diferents, però que foren elaborats per la mateixa mà degut a la seva semblança estilística. Les dues taules estaven desenganxades a l'església. 
El fet que no existeixi cap tipus de documentació sobre l'encàrrec d'obra, ni la seva manufactura impedeix conèixer certs aspectes bàsics i ha convertit aquesta recerca en una tasca difícil, laboriosa i poc concreta. A continuació tractaré de realitzar una aproximació al tema, procurant contextualizar les pintures.

\section{DESCRIPCIÓ I CARACTERÍSTIQUES DEL RETAULE}

Tot i que a les peces els hi manquen fragments de pintura, cal dir que es poden observar gran nombre de detalls de les escenes representades, aspecte que facilita la tasca d'anàlisi. És molt probable que aquest retaule fos confeccionat a finals del segle XV o principis del segle XVI per les seves característiques, ja que barreja elements propis del gòtic tardà $i$ del renaixement; però el mateix no devia anar signat, com era costum en moltes obres de l'època. Cal recordar que en aquells moments, si bé el pintor de retaules havia adquirit una certa consideració social, encara no acostumava en la major part dels casos a signar les obres. Les autories de les peces s'han conegut per mitjà de la documentació localitzada, o per comparació d'aquestes amb altres pintures que han servit de punt de referència. Molts artistes alternaven les obres de major i menor qualitat (l'introducció de daurats, de models iconogràfics nous, etc..., és a dir la preparació més acurada de la composició i el treball directe sobre la peça venien condicionats pel preu i les clausules establertes amb el comitent). Això ha fet difícil la tasca de l'historiador de l'art, ja que moltes vegades s'ha trobat amb obres d'atribució dubtosa i s'ha vist obligat a analitzar les posicions dels cossos, les semblances tècniques $\mathrm{i}$ altres factors possibles de captar en el retaule per aconseguir concretar més detalls. També cal esmentar que és molt probable que en les zones rurals no existís un contracte o documentació escrita i que moltes vegades els encàrrecs es fessin de paraula. En aquest cas es tractava d'una església rural com ja s'ha esmentat. I és quasi segur que una de les peces correspongués a aquella església. L'altre podria pertànyer a l'ésglesia parroquial de Sant Lleïr de Casabella (situada a uns 15 minuts de l'anterior), al peu de l'alt Cardener en el terme del municipi de Guixers, - si és que les dues taules no procedeixen d'un sol retaule, cosa probable degut a que també hi havia alguns retaules dedicats a dos sants o bé a un sant i una santa- i hagués estat traslladada a aquell lloc en algun moment, segons els testimonis dels habitants de la zona. Els personatges tot i que de característiques semblants no coincidieixen. Un 
és un home - ja que porta barba - i podria tractar-se de sant Lleïr i l'altre una dona, santa Magdalena, amb un cenyidor al cap que li recull els cabells. De totes maneres l'autor -encara que anònim- era el mateix i molt probablement es tractés d'un artista - potser local- que treballava a la comarca del Solsonès, i com veurem havia rebut certa influència de les tradicions religioses i iconogràfiques de la Catalunya Nord. Hi ha una tercera hipòtesi -menys probable sobre les peces - i seria el fer-ne una procedent de l'església dels Pascuets, pròxima a l'altra uns 15 minuts, sent llavors no sant Lleïr el personatge representat, sinó sant Llop, un bisbe màrtir, que sabem que a Catalunya fou venerat amb anterioritat i se li dedicaren altres capelles.

Les obres havien estat realitzades amb pintura al tremp sobre fusta de pi negre, tenen una forma rectangular amb la part superior arrodonida i les dimensions màximes de cadascuna són $68 \mathrm{~cm}$. d'alçada a la part central de l'arc, per $35 \mathrm{~cm}$. d'amplada, disminuint la seva alçada als costats en $56 \mathrm{~cm}$. degut a l'acabat semi-circular de la part superior ja esmentat. Aquesta forma semi-circular que mostren els retaules ens indueix a pensar en un acabat daurat als voltants del qual ja no en queda res, i el fet de tenir ambdues les mateixes dimensions reafirma la creença que es tractava de dues peces d'un mateix retaule. També es pot apreciar la preparació de la fusta abans de ser pintada i la presència d'un reforç a la cara posterior, format per dos llistons - un a dalt i l'altre a baix - clavats amb claus de forja.

Les imatges corresponen a vides de sants, tema que si bé comença a portar-se a terme durant el període romànic, és en el gòtic quan abunden els retaules dedicats a sants. Pel que fa als sants màrtirs, que semblen ser els representats a les escenes, es comencen a valorar a partir del s. IV, encara que la seva reproducció i interpretació freqüent s'inicia molt més tard. Moltes vegades el sant màrtir era un personatge evangelitzador que havia estat martiritzat per causa de la seva religió i ideologia, degut al fet d'haver-la adoptat i de voler-la propagar. A la taula on s'hi observa santa Magdalena, la figura està pregant i hi ha entre altres personatges un possible jueu - per la gorra amb ulleres que el protegia del fred, encara que era un barret emprat amb regularitat per moltes persones-, un jerarca i un rei amb una corona que presenta uns acabats d'influència musulmana, tots ells vestint túniques llargues; sembla una escena de martiri, ja que als seus peus hi ha un parell de personatges ajaguts i morts; per tant es tracta d'un assasinat col-lectiu. Ella de genolls està lligada a un marc de ferrar cavalls del tipus que tenien llavors els ferrers, símbol aquí de martiri com ho era la roda de molí o la de carro a la 
que de vegades es representaven lligats els personatges ${ }^{1}$. En canvi, el martiri de Sant Lleïr probablement, és un acte de Cort amb un conjunt de personatges de la realesa portant barrets propis dels membres de noblesa i les classes benestants de l'época (hi trobem el d'un jerarca o oficial, un mercader, el casquet d'un soldat a més del característic del monarca d'influència musulmana igualment), que contemplen com el sant és assotat amb una cua de cavall o de matxo per dos botxins, que van vestits de soldats amb una túnica curta i mitges fins els genolls; en canvi la resta de figures porta un vestit o túnica fins els peus. La ciutat no és pot identificar, però podria ser Roma al segle VI d.J. - si tenim en compte les referències trobades sobre el sant-, o bé la Jerusalem celestial ${ }^{2}$, degut a que era freqüent la seva representació com a símbol de la ciutat ideal i aquesta es feia per mitjà d'una perspectiva intuïtiva (encara no geomètrica); la ciutat amurallada servia com a mitjà de protecció contra l'enemic pagà $i$ de forma també simbòlica contra el seu món. Les notícies sobre sant Llop són molt menys precises, i hi ha molta llegenda entorn de la seva figura i vida.

La manera de treballar els cossos de les figures i les robes, la recerca d'un volum i d'un realisme apropen aquestes obres a la mentalitat prerrenaixentista. Tanmateix, les reconstruccions de ciutats que situen a la part posterior de les escenes sense utilització de daurats és un ingredient molt freqüent en aquest període, si bé a Catalunya trobem encara a finals del gòtic moltes obres amb fons daurats i uns plantejaments formals força arcaics; hi ha altres solucions pròpies del moment com és l'eliminació del daurat quasi per complet, excepte en els acabats dels mantells dels personatges i les aurèoles que s'ubiquen darrera els caps dels sants. Així la plasmació d'un cos nu o semi-nu —com en aquests casos-, encara que es tracti d'un martiri no es donava sempre, sinó que - com veurem- molts eren martiritzats vestits. Evidència una aproximació a la natura humana i a la realitat, que es concreta en la realització de l'escena en la qual el sant és martiritzat, i que pateix per causa de la seva fe. Hi ha la intenció de posar un espai natural o arquitectònic al fons de la taula, si bé aquest no es refereix a un lloc concret, sinó que normalment són un paisatge o construcció inventats, però que serveixen per

${ }^{1}$ L. Monreal y Tejada, Iconografía del Cristianismo, Barcelona, Ed. El Acantilado (Quaderns Crema, 37), 2000, pp. 543-544. L'obra s'ha emprat per a l'estudi iconogràfic de diversos conceptes: àngel (p. 441), ànima (p. 444), espasa (pp. 489-490), que s'interpreten en el mateix apartat.

${ }^{2} \mathrm{~J}$. SUREDA, La pintura gótica catalana del segle XIV, Barcelona, Els Llibres de la Frontera (Coneguem Catalunya, 26), 1989, p. 38. 
transgredir el món estrictament religiós i apropar-se per mitjà de la pintura a la naturalesa i la realitat qüotidiana. S'ha d'enquadrar el personatge representat en el món, ja que és vol explicar una part de la seva vida. L'obra té una finalitat biográfica, narrativa i històrica.

Tampoc trobem les figures dibuixades de cara en representació frontal, com en el Romànic, sinó un xic de costat. Les mateixes presenten encara uns traços poc espontanis, car s'observa una certa rigidesa i hieratisme en els cossos, moviments i actituds, tot i que es vol aconseguir fer persones de mides proporcionades i que s'apropin al cànon corrent. Aquesta solució suggereix una intenció nova, en voler mostrar per mitjà de la musculatura $\mathrm{i}$ el contrast lumínic, el sofriment del sant o santa. Aspectes que s'accentuen amb la distribució de la resta de figures i l'intent de representar un moment clau de l'acció; per exemple, el moment anterior o durant el martiri. Així es crea un clímax i s'inicia una seqüència que l'espectador de l'obra completa. En el cas de Sant Lleïr els dos botxins aixequen un o els dos braços i mouen el cos, al fons unes figures contemplen el martiri des d'una balconada -quatre dones i tres homes- i un conjunt d'arcades completa l'escena. Algunes figures porten corones - el rei i la reina-, son representades al centre i orientades cap a l'observació del sant -figura protagonista i central de l'escena- i tenen els cossos una mica girats, gesticulen i parlen. Hi ha una unitat formal que es completa amb els arcs semicirculars propis d'una construcció de l'época i una columna que sembla anunciar l'estil renaixentista, al copiar els autors les característiques de l'estil clàssic. També les decoracions de la balconada semblen remetre les propies de la Grècia antiga i del nou estil renaixentista.

En canvi, l'escena de santa Magdalena, conserva encara un element propi de l'art romànic, però l'enquadra en un nou contexte natural. Un àngel amb una espasa pot captar-se damunt l'escena principal, sembla protegir la víctima més que anunciar la seva salvació després de la mort física. L'espasa sol ser símbol de martiri i l'àngel acostuma a apareixer junt a molts sants; era llavors corrent que se'l pintés amb la Magdalena, ja que constituïa un dels ingredients de la seva iconografía. Projecta per tant una seqüència cronològica. La resta de personatges drets - vestits amb túniques i barrets- conversen entre ells i al-ludeixen al final d'una acció més que al seu començament com veurem. Ella és una religiosa i penitent que patí per causa de la seva fe. Per tant, en una mateixa imatge es concentren molts elements i es combinen, però igualment tots giren al voltant d'un personatge principal que consisteix en la santa agenollada i només vestida de mig cos amb els braços creuats en actitud 
d'oració. La representació d'aquesta figura mostrant els pits i una llarga cabellera és molt normal també, encara que aquí no la trobem despentinada. L'arquitectura del fons és una abstracció i té un to gris molt propi de les construccions pintades llavors; no es pot considerar una descripció d'una ciutat concreta, ja que sembla difícil que un pintor hagués tingut en aquella època una reproducció d'un dels llocs vinculats al sant o santa, en aquest cas de l'església de Vezelay o de la de Saint Maximin. Podria ser la ciutat celestial, com ja s'ha esmentat, perquè degut a la fe ella se salva. De fet Magdalena és presentada de vegades també com una pecadora arrepentida - sobretot seguint la tradició grecorromana- i s'han representat escenes del seu èxtasi, en les quals els àngels l'apropen al paradís; elements que suggereix indirectament el pintor en aquesta escena de martiri. Si bé sembla ser que el martiri no es realitzat pels personatges del món pagà antic o els jueus —encara que l'autor també ho té present-, sinó que per mitjà de l'escena rememora l'història de la invasió musulmana a l'Edat Mitjana; fusiona dos esdeveniments temporalment aillats, un de la primera etapa del cristianisme i l'altre posterior, ja que barreja vàries llegendes com veurem més endavant. Cal esmentar que els sarraïns atacaren el convent on vivia la Santa i la martiritzaren, encara que ella se salvà per causa de la fe. Els personatges situats darrera seu semblen pertanyer al món cristià, no hi ha cap botxí. El fet de posar un àngel en una escena de martiri ja s'havia donat en altres pintors anteriors, com en Lluis Borrassà ("Martiri de Sant Jordi"), o el taller de Martorell ("Martiri de Santa Clara", en el qual l'àngel també porta l'espasa del martiri). En altres ocasions, enlloc de l'àngel es representa una figureta petita elevant-se, es tracta de l'ànima del difunt o sant que puja cap al cel, com en el "Martiri de Sant Esteve" pintat per Jaume Serra, per exemple.

El problema consisteix en poder saber si les dues taules corresponien a un retaule dedicat a Sant Lleïr i Santa Magdalena, o bé si es tracta d'escenes que formaven part d'un retaule mes complicat d'estructura sobre la vida de Crist o de la Verge, si bé ens trobem amb una manca d'informació al respecte. Tot i que es tracta de conjectures molt possiblement ens inclinem per la primera opció degut al lloc on han estat trobats. 


\section{ANÀLISI DE LES FONTS CONSULTADES}

La manca de documentació, m'ha obligat a cercar una altra via per identificar les obres, consistent en la revisió de la bibliografía i les taules pintades que es troben als museus catalans ${ }^{3}$.

En primer lloc els treballs sobre l'estat de la qüestió en la recerca de l'art dels segles XIV-XV m'han servit de guia. Cal destacar en aquesta línia l'article d'Antoni José Pitarch "Pintura i miniatura gótica" $(1984)^{4}$, en el qual realitza una valoració de la historiografía, comenta les aportacions concretes dels autors i les obres, destacant entre d'altres la de Josep Gudiol, qui alguns anys després revisà la seva, de 1936 i en va escriure una altra versió amb Santiago Alcolea i Blanc, "Pintura gótica catalana" (1987) $)^{5}$, aquest s'ha convertit en un llibre de referència de gran importancia perquè sintetitza un nombre molt ampli de continguts sobre els artistes (dades, fonts documentals i fotografíes). També Pitarch valora les publicacions monogràfiques i es refereix als estudis concrets portats a terme sobre pintors. Igualment Rosa $\mathrm{M}^{\mathrm{o}}$ Terès a "Escultura y pintura góticas. Estado de la cuestión" $(1997)^{6}$ establí una nova valoració, en la que va destacar el mateix text de Gudiol i comentà noves monografies, catàlegs de museus, etc... Ella esmentà el llibre de Joan Francesc Ainaud "Ars Hispaniae" i el de Núria de Dalmases i Antonio José Pitarch, "L'art gòtic, s. XIV-XV" (1988) ${ }^{7}$ obra en la qual es concreten moltes notícies i es destaquen les escoles i centres importants.

Si els texts de Pitarch (1984) i el de Terès (1997) em serviren per conèixer la bibliografía, els de Gudiol/Alcolea i el de Dalmases/Pitarch m'ajudaren a aprofundir en les característiques de les peces, estil i escoles. Per tant, em guiaren cap a autors concrets i el seu anàlisi. No vull destacar les

${ }^{3} \mathrm{He}$ consultat les obres del Museu Nacional d'Art de Catalunya (Barcelona), Museu Diocesà de Barcelona, Museu Diocesà i Comarcal de Solsona, entre d'altres.

${ }^{4}$ A. J. PITARCh, Pintura $i$ miniatura gótica, a "Congreso CEHA. Arte catalán. Estado de la cuestión”, Barcelona, Diputació, 2004, pp. 259-267.

${ }^{5}$ J. Gudiol; S. AlCOLEa I BlanCh, Pintura gótica catalana, Barcelona, Ed. Polígrafa, 1987, 494 p. e ils.

${ }^{6}$ R.M ${ }^{\text {a }}$ TERÈs, Escultura y pintura góticas. Estado de la cuestión, a "Cathalonia. Arte gótico en los siglos XIV-XV", Madrid, Museo del Prado, catálogo exposición. Ministerio de Cultura, 1997, pp. 31-46.

${ }^{7}$ N. DE Dalmases; A.J. Pitarch, L'art gòtic. S. XIV-XV, a "Història de l'Art Càtala", Barcelona, Edicions 62, vol. III, 1988, pp. 101-277. 
aportacions de cada llibre, ni els seus plantejaments, ja que aquesta tasca m'apartaria dels aspectes concrets que ara estic observant.

Altres treballs com els de Sureda $(1997)^{8}$ em facilitaren la comprensió de les obres del periode, pel tipus d'anàlisi compositiva, temàtica i simbòlica que utilitza, i per la contextualització i síntesi que estableix. Junt amb alguns articles que em varen permetre aprofundir en el entorn temàtic com el de Francesc Ruiz Quesada, "Imagen artística y economía de la pintura catalana de los siglos del gótico" (1997) .

Tot i que vaig utilitzar altres obres, com la de Gabriel Llompart, "La pintura medieval mallorquina. Su entorno cultural y su iconografía" $(1977)^{10}$ amb la finalitat d'ampliar l'àmbit geogràfic. L'aproximació posterior a monografies d'art per tractar d'observar semblances entre les dues taules i les dels autors ja estudiats em portaren a interessar-me pels treballs publicats que guardaven una referència amb artistes de la zona de Lleida i sobre tot pels que feien encàrrecs a la part del Solsonès. Em cridaren l'atenció les publicacions de Rosa Alcoy, "Pintures del gòtic a Lleida" $(1990)^{11}$ amb aportació de noves teories sobre pintures concretes, -encara que se centrava en el s. XIV i les taules de Santa Magdalena cal datar-les en una etapa posterior- i la coordinada per Ximo Company, "La pintura gótica dels Ferrer i altres aspectes (in)coneguts al voltant de la Seu Vella de Lleida. S. XIII-XVIII" $(1998)^{12}$ que completava l'estudi sobre el gòtic a Lleida, en aprofundir en la tasca efectuada per una família molt destacada d'artistes Jaume Ferrer I i Jaume Ferrer II. Després de llegir aquests volums i de repasar les obres concretes d'aquests autors no vaig considerar -com veurem- que tinguessin res a veure els retaules estudiats amb la labor d'aquest grup d'artistes, ni a

${ }^{8}$ J. SUREDA, Ob. Cit., p. 208. i J. SUREDA, Algo sobre lo Internacional en la pintura gótica catalana y la internacionalidad de ésta, así como sobre los impedimentos para discernirlo justamente, a "Cathalonia. Arte gótico de los siglos XIV-XV", Madrid, Museo del Prado. Ministerio de Educación y Cultura, 1997, pp. 21-29.

${ }^{9} \mathrm{~F}$. RUIZ QUESADA, Imagen artística y económica de la pintura catatalana de los siglos del gótico, a "Cathalonia. Arte gótico de los siglos XIV-XV", Madrid, Museo del Prado. Ministerio de Educación y Cultura, 1997, pp. 67-80.

${ }^{10} \mathrm{G}$. LlOMPART, La pintura medieval mallorquina. Su entorno cultural y su iconografía, Palma de Mallorca, Lluis Ripio Editor, 1977, 4 vols.

${ }^{11}$ R. Alcoy, Pintures del gòtic a Lleida, Lleida, Cercle de Belles Arts de Lleida. Col·legi oficial d'Aparelladors i Arquitectes Tècnics de Lleida. Estudi General de Lleida, 1990, 144 p.

${ }^{12} \mathrm{X}$. COMPANY; I. PUIG (Coordinadors), La pintura gòtica dels Ferrer $i$ altres aspectes (in) coneguts al voltant de la Seu Vella de Lleida, s. XIII-XVIII, Lleida, Amics de la Seu Vella, $1998,385 \mathrm{p}$. 
nivell iconogràfic, ni a nivell compositiu o formal. Si bé ens referirem a continuació de manera més descriptiva i detallada a l'àmbit lleidatà, en el qual he centrat pràcticament el meu treball.

\section{L'ESCOLA DE LLEIDA}

Les pintures trobades a Santa Magdalena de les Tragines no es poden atribuir a cap dels autors coneguts que desenvolupaven la seva tasca en aquella zona de Lleida. Ni tampoc a d'altres procedents de la part de Girona. Cal per tant considerar-les anònimes, ja que si bé conserven elements propis de l'època, els recursos adoptats són personals i semblen més tardans.

De l'Escola de Girona he revisat l'obra de Joan Antigó (...14071453...), Mestre de Castelló d'Empúries (2a. meitat del segle XV), Ramón Solà (...1424-1462), Ramón Solà II (...1456-1484/94), Esteve Solà (...1456$1467 . .$.$) , però tot i que corresponen al segle XV en general es tracta d'obres$ amb solucions formals més arcaiques; els personatges van totalment vestits i no semi-nusos com en les escenes estudiades. En les taules de Joan Antigó, per exemple, trobem a la Verge en posició agenollada i amb les mans creuades com a símbol d'oració, tal i com s'aprecia en el retaule dedicat a Santa Magdalena i la seva proximitat estilística és més gran que en la resta d'autors.

Encara que l'àmbit lleidatà ha estat estudiat per Rosa Alcoy $(1990)^{13}$, —com ja s'ha esmentat- ella es dedicà bàsicament al segle XIV i a la corrent italianitzant anterior. Cal destacar els aspectes referents a Jaume Ferrer I, ja que posà de manifest la problemática existent entre aquest autor i un possible Jaume Ferrer II per desconeixement de si les influencies estilístiques es podien considerar com una evolució del mateix autor, o bé eren obra d'una altre mà (el seu fill). Revisava en el seu llibre algunes atribucions. Els autors varen ser després estudiats amb més cura per Ximo Company i Isidro Puig Sants, sobretot pel que fa a la Seu de Lleida ${ }^{14}$, si bé portaren a terme una relació d'obres atribuïdes classificant de nou la producció d'ambdós pintors.

\footnotetext{
${ }^{13}$ R. ALCOY, Pintures del gòtic a Lleida, p. 23, suggereix futurs debats entorn dels artistes Jaume Ferrer I i II.

${ }^{14} \mathrm{X}$. COMPANY; I. PUIG (Coordinadors), La pintura gòtica dels Ferrer $i$ altres aspectes (in) coneguts al voltant de la Seu Vella de Lleida. S. XIII-XVIII, Ob. Cit., 385 p. 
Pel que fa a l'Escola de Lleida, si bé molts dels seus representants reberen l'influència dels germans Francesc, Jaume, Pere i Joan Serra (obres $\mathrm{amb}$ acabats minuciosos $\mathrm{i}$ construïdes per mitjà de personatges amb rostres detallats, dinamisme i que portaven vestidures luxoses) amb taller a Barcelona, no guarden una relació directa amb els retaules de Les Tragines. Jaume Ferrer I (nascut a Lleida), considerat ja un autor pertanyent al Gòtic Internacional, encara que visqué a finals del s. XIV i principis del s. XV i amb obra de la seva darrera etapa al Museu Diocesà i Comarcal de Solsona, ("L'Últim sopar", per exemple, tot i la vàlua d'aquesta peça sobretot pel detallisme amb que representà la vaixella de ceràmica, les culleres i ganivets, no aconseguí en canvi plasmar rostres individualitzats totalment i les fesomies dels apòstols mostraven certa semblança), rebé inicialment l'influéncia de Pere Serra. Però també es deixà influir després per la tendència de Lluis Borrassà i per la pintura valenciana. És difícil de resseguir-li la vida, ja que aquesta no està documentada, ni tampoc el seu treball. Una part dels seus retaules es troben al Museu Diocesà de Lleida ("Epifania", obra signada ${ }^{15}$, o "Retaule del Salvador" d'Albarratec), encara que realitzà obra per l'església de Sant Antoni de la Granadella, i també en té a Tamarite de Litera, Benavarre, Estopiñán, etc... ${ }^{16}$; és a dir a la part de Lleida i Aragó. Hi ha un altre Jaume Ferrer II, considerat el fill del primer, per algunes semblances estilístiques i formals, si bé la seva pintura està més documentada (entre 1430 a Barcelona i 1461 a Lleida). Ambdós treballaren a la Seu de Lleida i a altres poblacions de l'àmbit lleidatà; així el "Retaule de Verdú" (1434)(Museu Episcopal de Vic) és considerat la primera obra de l'autor ${ }^{17}$ en la qual mostra una gran influència del seu pare; en té d'altres a Sant Julià de Aspa, etc.. La seva labor pictòrica queda inclosa també dins l'àmbit del Gòtic Internacional, però resulta molt més fàcil de resseguir. Tanmateix la seva evolució i influències — primer de Lluis Borrassà per relacions familiars i després de Bernat Martorell amb qui treballà a la Seu de Lleida- són més clares.

\footnotetext{
${ }^{15} \mathrm{X}$. COMPANY, Aspectes ignots dels artistes medievals, a "La pintura gòtica dels Ferrer i altres aspectes (in)coneguts al voltant de la Seu Vella de Lleida, s. XIII-XVIII", Ob. Cit., pp. 6869.

${ }^{16}$ J.F. RÀFOLS, Diccionario biográfico de artistas de Cataluña, Barcelona, Ed. Millà, 1951, vol. I, p. 391

${ }^{17}$ I. PUIG SANCHÍs, Los Ferrer, una familia de pintores leridanos vinculados con la Seu Vella de Lleida, a "La pintura gòtica dels Ferrer i altres aspectes (in)coneguts al voltant de la Seu Vella de Lleida, s. XIII-XVIII", Ob. Cit., pp. 68-69.
} 
Jaume Ferrer I incloïa en les seves taules arquitectures i fons de paisatge; feia un tipus de construccions molt semblants a la que hi ha plasmada al retaule de Santa Magdalena de les Tragines. En la seva obra "Martiri de Santa Llúcia" (Museu Diocesà de Lleida) la santa apareix en la mateixa actitud que Santa Magdalena: agenollada i amb les mans creuades com si estigués resant - posició que es repeteix en moltes figures de l'època: una persona agenollada amb les mans en actitud de resar, vestida o bé semi nua-. De totes maneres tot i que hi ha una certa influència o semblança, l'estil del traç no és el mateix, ni la manera de treballar el volum, o les ombres dels personatges i robes; és més: acostumava a emprar aquests daurats que no es poden apreciar en el de les Tragines.

També trobem en Jaume Ferrer II la figura de la Verge en una postura semblant a la de Santa Magdalena, però normalment els personatges que representa agenollats van completament vestits. Insinua una perspectiva i el caracteritza l'ús d'indumentària luxosa, sanefes i riques teles, elements que l'apropen al Gòtic Internacional. Jaume Ferrer II empra també els fons daurats i la distància amb l'obra de l'autor anònim estudiat és més accentuada, tot $\mathrm{i}$ la seva major proximitat temporal. En canvi, hi ha una certa aproximació a Jaume Ferrer I en el tractament del volum de les figures i la fisonomia dels rostres; tanmateix en l'austeritat que trobem en les vestimentes i acabats, si el comparem amb el seu fill. Un exemple clar el tenim en l'obra esmentada sobre el "Martiri de Santa Llúcia", si bé en les taules de santa Margarida la configuració dels membres del cos és més realista i estructurada, la qual cosa fa pensar que aquest artista coneixia la pintura de Jaume Ferrer I; encara que la producció del primer portava un segell personal i evidentment presentava les característiques pròpies d'una etapa més tardana pel que fa al realisme de les figures, o a l'estructuració general de l'escena i acabats.

Un altre pintor que estigué vinculat a la zona de Lleida fou Pere Vall (documentat entre 1405-1411), també influït per l'obra de Pere Serra. Aquest se'l considera un representant del Gòtic Internacional, que treballà bàsicament a Cardona, lloc on havia nascut, realitzant obres per l'església parroquial de Sant Miquel: Sant Pere, Sant Blai, la confraria del Sant Esperit i Santa Anna. Juntament amb altres com el de Sant Vicenç per a la Colegiata de Sant Vicenç de Cardona. Tot i que en el conjunt de la seva pintura s'hi observa un predomini dels elements arquitectònics i la plasmació de figures verticals d'un tamany força gran, l'única semblança que s'ha trobat amb les peces estudiades és al "Martiri de Sant Blai" (1408). El sant se'l representa nu de mig cos i agenollat esperant el martiri, porta la mitra episcopal. La posició del cos de 
la figura s'assembla, si bé l'orientació de la mateixa es l'oposada a la de santa Magdalena. Alguns autors consideren que aquest artista va influir probablement a Jaume Ferrer $I^{18}$. De totes maneres en les obres conservades al Museu Diocesà i Comarcal de Solsona, "Baptisme i Anunciació" s'aprecia una influència de Lluis Borrassà, tot $i$ tenint en compte el hieratisme i la frontalitat dels personatges de Pere Vall. El darrer procura que els rostres mostrin una expressió individualitzada, aportant mobiliari i detalls arquitectònics en les escenes, encara que continua mantenint els fons daurats.

El problema més greu a la hora de trobar referències consisteix en l'arcaisme que persisteix en els treballs dels artistes de finals del s. XV i que es manifesta tant en la presentació de l'escena, la poca perspectiva i l'abundància de daurat, entre d'altres aspectes que si bé ja s'han esmentat cal remarcar. Crec que tot i que el retaule pertany al Gòtic Internacinal, aquest rep una influència directa pel que fa als motius i les tradicions iconogràfiques i temàtiques del Sud de França. Per aquest motiu presenta unes característiques que l'aparten de la tradició propia de la zona lleidatana.

\section{Altres ASSUMPTES}

RELACIONATS AMB MARTIRIS I ACTITUDS DE FE

Tractarem de configurar un estudi formal i compositiu en aquest apartat, ja que dedicar-nos a l'interpretació de la vida concreta de cada sant i santa esmentats complicaria l'anàlisi i portaria l'estudi cap a altres àmbits que de moment no interessen. Parlarem després d'aquests aspectes i ara ens centrarem en les escenes de martiri. Les més corrents eren les lapidacions, les cremacions a la foguera i les flagel-lacions.

Pel que fa als martiris femenins, podem destacar el de Santa Perpètua, una obra pintada al tremp i datada entre els anys 1290 i 1325, la qual es troba al Museu Diocesà de Barcelona i que pertany a un frontal dedicat a la santa. A una de les escenes s'observa el martiri de la santa, situada a la dreta, de cara, agenollada i amb els braços junts en senyal d'oració. Al seu costat el botxí l'assota amb una cua de cavall. Es tracta d'una peça amb solucions arcaiques pel que fa al moviment, el volum i el realisme de les figures. També

${ }^{18}$ I. PUIG SANCHÍs, Los Ferrer, una familia de pintores leridanos vinculados con la Seu Vella de Lleida, Ob. Cit., p. 157. També va recollir en les seves composicions l'influència de Ramon de Mur (p. 160). 
el fons és llis. A l'esquerra un rei observa l'escena assegut amb actitud d'aprovació, i aixeca un dels dits de la seva mà dreta. Aquest personatge el trobem reproduït amb freqüència en aquest tipus d'escenes.

El martiri de Santa Llúcia ha estat més representat. Cal destacar el pintat per Joan Mates (Barcelona,1391-1431), en el que es veu la santa agenollada i vestida amb luxe. Té les mans juntes en posició d'oració i al seu darrera s'hi troba la foguera. Un grup de cavallers amb llances estan situats al fons, i en primer pla n'hi ha un altre que sosté una llança mentre la vigila. L'obra es conserva al Santuari de Penafel, a Santa Margarida i els Monjos (Alt Penedès), si bé pertany a la col·lecció Olavarria. Igualment Jaume Ferrer I representà el martiri de la santa en una taula que es troba al Museu Diocesà de Lleida. La santa agenollada i en posició de tres quarts, està orientada en sentit invers a la representada per Mates, va semi-nua i té els braços aixecats en actitud d'oració i de pietat; al seu costat hi ha també un botxí, contrariament a la de Mates, té un paisatge al fons. En canvi, Ferrer finalitza l'escena amb un fons llis. Tot i que pertany al primer terç del segle XV, sembla més arcaica i conté menys profunditat i perspectiva que la de Mates. La mateixa santa en l'escena esmentada també va ser realitzada per Bernat Martorell, que pintà el martiri d'aquesta cap el 1435, amb una actitud molt semblant a la de Mates, la mateixa va totalment vestida, està quasi de perfil agenollada i amb les mans juntes, la han lligat a un pal per cremar-la viva i sota els seus peus un botxí atia el foc; dos personatges li tiren oli bullent i la resta s'ho mira. Al fons s'hi ha plasmat una muntanya i un acabat daurat. El pintor, la representà en una altra ocasió - llavors el botxí portava una llança- ajuntant aquesta escena amb la de la comunió que donaren uns capellans a la màrtir, com va fer igualment Jaume Ferrer I en la seva obra. No presenta les figures dels guerrers al fons. L'obra pertany a la col-lecció de Miguel Torres de Barcelona.

Els continuadors del taller de Martorell feren uns retaules dedicats a santa Clara i santa Caterina, que en un primer moment es trobaven a la capella de santa Clara de la Catedral de Barcelona (1454-1458). Es pot apreciar en la taula del martiri de santa Caterina a aquesta agenollada i amb una roda al seu costat, orientada en direcció a l'esquerra en posició de tres quarts, manté els braços junts amb actitud de resar. Va vestida amb luxe i porta corona. Nombrosos personatges ben vestits, amb barrets i llances observen l'aconteixement, solució també corrent i que localitzem en altres obres, ja que el martiri se solia portar a terme en un lloc públic, tant si es tractava d'un àmbit exterior com interior. $\mathrm{Al}$ fons un paisatge i un edifici amb 
nombroses finestretes romàniques i una gran porta completen la peça. Hi ha una voluntat de complexitat en tota l'escena. Un àngel al seu damunt, que porta una espasa, la protegeix.

Finalment una obra més tardana (1535-36) pintada al tremp i a l'oli de Jaume Fornell, procedent de l'església de Santa Agnès de Malanyanes i ara custodiada al Museu Diocesà de Barcelona. Curiosament l'escena passa a dintre d'una habitació, comunicada amb dues portes. A la porta central s'hi ha pintat un cel daurat. La santa amb cabells llargs està agenollada al centre de la composició i té les mans en senyal d'oració. El botxí ja ha posat l'espasa al coll de la santa i és a punt de tallar-li amb un punyal; ella en posició de genolls damunt de troncs encesos acabarà cremada viva. Uns personatges situats a la dreta s'ho miren, i a l'altra banda uns altres giren el cap sense donar importància al fet i continuen la seva marxa. Per les característiques semblen persones benestants, porten túniques i barret. Tot i que transcórre en un escenari interior, la disposició de les figures facilita la sensació de perspectiva i els elements daurats són quasi inexistents. Els volums i les formes de les figures estàn totalment aconseguits i la columna del fons al-ludeix ja al moment renaixentista, que es deixa influir per la decoració i el gust clàssic.

Pel que fa al martiri de santa Bárbara, aquest va ser per lapidació. Així ho representà el mestre de Santa Bassilissa al segon terç del segle XV. Al Museu Nacional d'Art de Catalunya (Barcelona), es guarda l'obra i s'hi poden observar dues escenes: 1) Ella agenollada i en posició de tres quarts, mentre un nombre de personatges l'apedreguen. $\mathrm{Al}$ seu costat hi jauen altres persones ja mortes, un fons de paisatge i muntanyes completa la imatge. 2) La santa, de genolls, és degollada per un botxí davant d'unes persones que s'ho miren; l'escena s'ha resolt d'una manera semblant. Una altra representació de santa Bàrbara la confeccionà el pintor Gonçal Perís-Sarrià de València (13801451) pel retaule de l'església de Puertomingalvo (Terol), on hi presentà la mort per lapidació de la santa, deguda a tres botxins. Ella va ben vestida i la situa de perfil a un costat de la peça, amb les mans juntes. Al fons hi disposa una construcció amurallada i acabats en daurat.

Els martiris femenins escollits contenen unes característiques similars pel que fa a la posició del cos i actitud de la màrtir, inclouen quasi sempre un o dos botxins - exceptuant els que son fets per lapidació- i normalment algun personatge de la cort en un fons arquitectònic o paisagistic; fins i tot en les obres procedents de Valencia o l'Aragó trobem paral·lelismes iconogràfics, i el treball per encàrrec portava als artistes a desplaçar-se dins d'un àmbit 
geogràfic força ampli, que els facilitava el rebre influències forànies. La taula de santa Magdalena de les Tragines presenta unes característiques molt semblants, també hi ha un àngel damunt de la figura, si bé no es pot considerar una còpia, ni un punt d'inspiració en aquesta obra, ni directament en altres, ja que compositivament i formalment cadascuna mostra uns trets diferents, que reflecteixen una creativitat personal. No s'ha trobat cap escena de martiri de santa Magdalena, exceptuant la estudiada, si bé es tracta en aquesta ocasió d'un assassinat col·lectiu o martiri de grup, al qual sembla que la santa sobrevisqué. No hi ha cap botxí a punt d'assasinar-la, sinó personatges que la contemplen i parlen entre ells. El curiós és que s'hi hagi dibuixat un àngel damunt seu, ja que no se sol plasmar sovint aquest element damunt del màrtir durant l'Edat Mitjana, cosa que ens fa pensar que es tracta d'una obra lleugerament més tardana.

Pel que fa als martiris masculins, he sel·leccionat alguns que guarden una certa similitud amb els procedents de Les Tragines i he trobat un nombre més elevat de peces semblants que en els femenins; si bé en aquests martiris l'escena resulta més pròxima al martiri de Santa Magdalena que al de Sant Lleïr. Les descriuré a continuació per ordre cronològic. Jaume Serra pintà al retaule de Sant Esteve el seu martiri. La peça inicialment feta per la localitat de Gualter (La Noguera), es conserva ara al Museu d'Art de Catalunya. Encara que es tracta d'una escena arcaica amb el fons de muntanyes i un cel daurat, s'observa el sant en posició de perfil, agenollat i mirant cap amunt en actitud d'oració. Un grup de persones li tiren pedres i la resta contempla l'escena; sembla que vol eliminar l'antiga llei dels jueus per abraçar la fe cristiana. En el retaule de Sant Joan Baptista i Sant Esteve realitzat per a l'església de Santa Maria de Badalona efectuà el martiri per lapidació de sant Esteve, el qual el situà de perfil i agenollat, pregant amb els braços, mentre quatre persones li llençaven pedres. Igualment l'obra inclou la imatge d'una ciutat amurallada i un fons daurat. També Bernat Martorell (1400-1452) en el retaule de la Transfiguració, pintà a sant Esteve de genolls, en el moment de ser assotat davant d'una sèrie de persones que s'ho mira, completant la taula amb un fons daurat.

Una mica abans Lluis Borrassà (1380-1425) havia ideat dos retaules en els quals inclogué escenes de martiri: el dedicat a la Verge i Sant Jordi a l'església del convent de Sant Francesc de Vilafranca del Penedès on hi trobem el sant també lligat a una roda, agenollat i resant amb les mans juntes; mentre un botxi fa girar-la. Es tracta d'una escena doble, ja que també el crucifiquen després. Tot i que hi ha una arquitectura, porta un fons d'or. 
Tanmateix en el retaule procedent del Convent de Santa Clara de Vic, hi ha la representació del martiri dels sants Judes i Simó. L'obra en l'actualitat es custodia al Museu de Vic. En un primer plà es veuen els dos sants agenollats en posició de tres quarts - cara a cara- i completament vestits, voltats de personatges del món eclesiàstic, degut a que porten la mitra episcopal. Un d'ells aguanta una espasa amb l'intenció de tallar-los-hi el coll. Un altre tema de martiri es el que porta a terme sobre Sant Blai per l'església de Sant Miquel de Cardona, i que en l'actualitat pertany a una col·lecció privada; en l'esmentada peça Pere Vall (1405-1411) el presenta agenollat amb una corona. Tres personatges amb un bastó l'assoten. El sant és al centre, en posició de tres quarts agenollat, només un petit drap cobreix la part inferior del seu cos, $i$ té les mans creuades i lligades. A un costat un rei entronitzat contempla l'escena i a l'altre una dona rep la confessió del sant. Es tracta d'una escena doble també. Hi ha altres figures de la Cort i el sant llueix la mitra episcopal. Una muralla amb una porta i tres torres completen la part del fons. Tot i que no es tracta d'una obra molt avançada en la seva composició, el daurat es redueix als acabats de les torres i el cel - que quasi no es veu.

De la segona meitat del $\mathrm{s}$. XV és el retaule de sant Romà situat a la capella de "Can Santromà" (Tiana, Maresme) que pertàny a la família Vergós. El sant va ser martiritzat a la foguera. En l'escena el sant està agenollat i completament vestit amb riques robes. S'hi representen tres figures, una de les quals amb un punyal talla el coll del sant. En aquest cas el cos està ajupit i no agenollat, ja que li falta el cap, per tant els recursos que adopta són força diferents. He procurat ometre les cremacions de sants excepte aquest, ja que consisteix en un tema força recurrent. En una obra anònima del darrer quart del segle XV (Museu Diocesà de Barcelona) s'observen altres dues escenes: el martiri i la decapitació de sant Bartomeu. En el martiri, el sant se'l presenta agenollat i ben vestit, gesticulant amb les mans. El botxí el pica amb un bastó. Cinc persones de la Cort miren el que passa, les tres disposades darrera del sant semblen trobar-se a punt d'intervenir, sobretot un d'ells que ja té la mà aixecada. L'aconteixement passa en un interior i un petit fons daurat no deixa veure el paisatge de l'exterior. Una altra peça també anònima de finals del $\mathrm{s}$. XV és la que correspon al martiri d'ambdós i es troba al retaule de Sant Quirze i santa Julita de l'església dedicada al sant a Arbúcies (La Selva). El de la santa es porta a terme amb una serra i el de l'esmentat sant, consisteix en una flagel.lació per part d'un botxí que l'assota amb una cua de cavall, mentre altres personatges contemplen l'escena; aquest està agenollat amb les mans juntes com a símbol de 
pregària, sense vestits; entre el públic s'hi troba un home entronitzat que sosté un nen petit, el qual mostra interés en protegir-lo, ja que té l'intenció de donar-li la mà. Molt possiblement es tracti de la figura de Jesús. Un fons de paisatge i unes muralles acaben l'escena.

El martiri per flagel-lació era corrent entre els sants, per aquest motiu apareix de vegades en els retaules. El que caracteritza a la peça estudiada de Sant Lleïr en relació a les altres -encara que se'n pot trobar algun altre cas semblant- és la posició de la figura, quasi d'esquena, semi-nua i amb els braços lligats a una columna en posició de ser assotada, ja que la disposició del personatge principal quasi d'esquena no resulta ser gaire freqüent. També el fet d'haver-hi dos botxins, un a cada costat aixecant els braços, per picarlo, un amb una cua de cavall i l'altre amb un bastó, resulta ser molt valuós, ja que aquests elements se'ls considera característics i es troben presents en altres flagelacions de l'època.

Tant en l'obra estudiada com en la de Bernat Martorell anomenada retaule de Sant Vicenç (1438-40) efectuada per a l'ermita de Santa Creu de Menàrguens (Noguera), al sant se'l situa en un interior semi-nu i de peu, en el moment de ser flagel-lat per dos botxins, encara que no hi ha cap observador. Aquesta solució la repeteix en el retaule de Sant Miquel, martiri de santa Eulalia i Santa Caterina (1442-45) procedent de l'església de Banyetes de Penedés; si bé el darrer s'apropa més a la iconografía dels retaules estudiats que l'altre, ja que la santa la mostra semi-nua i agenollada. També inclou a darrera molts personatges que s'ho miren, destacant un d'ells que seu en un tron; encara que l'escena té lloc a l'interior d'una habitació, el fons és daurat.

En la representació de Sant Lleïr no hi ha daurats, sinó que ja ens trobem amb una sèrie d'elements propis del renaixement com són: la profunditat en l'escena, el volum i moviment de les figures, la integració i cohesió entre els personatges i la col·locació d'arquitectura i mobiliari és molt més abundant, junt amb la inclusió d'algun detall nou propi de l'estil renaixentista com els acabats semi-circulars dels arcs de finestres i portes. Una altra flagel-lació corresponent a finals del segle XV i principis de la meitat del segle XVI que es guarda al Museu Nacional d'Art de Catalunya (Barcelona), és la realitzada pel Mestre de Castelsardo, en la que plasma a Sant Vicenç (1500-1510) amb les mans lligades, voltat de personatges i soldats. Un d'ells seu en un tron, mentre mira com dos botxins assoten al sant, l'un porta un bastó i l'altre utilitza una cua de cavall. Es tracta d'una solució més propera a la de sant Lleïr, tant pel que fa a la disposició de dos botxins, com per l'ús d'unes determinades eines de martiri; aquests aspectes 
ens permeten observar uns canvis lleugers en la composició de les obres més tardanes. Cal esmentar que la darrera consisteix en una peça feta al tremp, que formava part del retaule major de l'església de Sant Vicenç de Sarrià.

\section{LA REPRESENTACIÓ DE SANTA MAGDALENA, SANT LLEÏR I SANT LLOP}

La imatge de Santa Magdalena apareix amb freqüència a l'Edat Mitjana a partir del gòtic, si bé se sol representar a la santa relacionada amb la persona i vida de Crist, en els episodis vinculats a la Verge i sant Joan Baptista, o bé amb altres figures de sants: casa del fariseu, casa de Marta i Maria, resurrecció de Llàtzer, Crucifixió, plors per la mort de Crist, les tres Maries davant el sepulcre, etc... ${ }^{19}$ D'aquesta figura hem localitzat més de 50 imatges; de vegades només se la reprodueix dempeus i descontextualitzada. Pel que fa als retaules dedicats a aquesta santa hem trobat el de Pere Valldebriga (..1360-1405..) a la Catedral de Barcelona; un altre realitzat per pintors anònims de la regió del Segre, avui conservat al Museu Nacional d'Art de Catalunya de la ciutat esmentada, i un altre de Jaume Huguet (1415-1492) que es troba a una col·lecció privada. En la resta de casos, la santa forma part d'escenes en retaules dedicats a la vida de Crist i de la Verge. Entre les seqüències més habituals en les que la santa és protagonista hi ha l'assumpció, pintada per Ramon Destorrents (..1351-1362...) en un retaule dedicat a la santa que es troba al Museu del Prado (Madrid) i que abans es conservava al Santuari de Nostra Senyora de Tobed (Zaragoza), i un altre del mestre de Fonollosa (primer quart del segle XV), avui al Museu Episcopal de Vic. O bé el de Bernat Martorell (primera meitat del s. XV) on s'observa en una taula a la santa servint a Jesús, els apòstols i després en una altra dedicada a l'assumpció que es conserva en l'Església de Santa Maria Magdalena de Perella (Ripollès), o en la pintura de Ramon II i Esteve Solà (segona meitat del s. XV) que representaren també la seva assumpció en un retaule dedicat a sant Bartomeu, procedent de l'església parroquial de Santa Eulàlia de Cruilles, avui al Museu d'Art de Girona. Existeix un retaule anònim dedicat a la santa que es custodia a l'església de Bell-Lloc (Tarragona, 1495-1504), en aquest s'amplia el nombre i la temàtica dels episodis exposats: la santa i els

${ }^{19}$ S. ZUFFI, Episodis i personatges de l'Evangeli, Barcelona, Ed. Electa, 2003, p. 179, 188, 192, 216, 250, 292, 312, 348. 
seus companys resten abandonats en una barca a alta mar, la santa és aixecada pels àngels, el bisbe sant Maximinià li dóna la darrera comunió, la santa renta els peus de Crist, etc.

En canvi les fonts i texts ens apropen a un gran nombre de santes magdalenes, com per exemple les explicacions que consten en la col.lecció "Biblioteca Sanctorum" $(1966)^{20}$, si bé totes les persones que descriu no tenen res a veure amb aquesta figura ja que les seves accions tingueren lloc en un moment posterior a l'Edat Mitjana, per tant cap d'elles correspon a la santa estudiada; tanmateix no són espanyoles. Esmenta a Magdalena arxiduquesa d'Austria (1532-1566), Magdalena de la Mare de Déu, una monja que visqué entre 1769-1792 a Bollene, Magdalena de Sant Josep, nascuda a París el 1578 i que morí el 1650, Magdalena del Santíssim Sacrament de Bollene (1743), i Magdalena Sofia Barat originaria de Joigny (1779), la qual morí a París el 1865. El llibre on s'han trobat més referències sobre la santa vinculada a Crist ha estat el de Lluis Réau, "Iconographie de l'Art Chrétien" $(1958)^{21}$. En primer lloc fa una aproximació i diu que no hi ha un acord entre els teòlegs sobre la seva persona, ja que poden ser tres personalitats diferents fusionades en una sola segons la llegenda. No la considera una màrtir. Segons una descripció és Magdalena de Betania germana de Marta i Llàtzer. Entre les escenes més representades de Santa Maria Magdalena s'hi troben: l'instant en que neteja els peus de Crist, el moment de la resurrecció de Crist, o el de la resurrecció de Llàtzer. Aquest autor reflexiona sobre la seva vida després de la mort de Crist i resurrecció. Hi ha una llegenda greco-romana que diu que es va retirar a Èfes amb la Verge i allà morí. Però en una altra llegenda forjada a Borgonya el s. XI, entorn de les seves reliquies, diu que aquestes no foren depositades a Constantinopla — com en el cas anterior- sinó a Vezelay. Aquesta parla sobre la seva arribada a Marsella acompanyada del bisbe Maximí d'Aix-en-Provence i les santes Maries, la seva germana Marta i el seu germà Llatzer, la conversió d'un príncep pagà i el seu recolliment al desert per fer penitència en una cova fins abans de la seva mort, ja que llavors fou traslladada a Aix-en-Provence on sant Maximí li donà la darrera comunió i uns àngels la transportaren a un oratori, espisodi escassament mostrat. Si

${ }^{20}$ Biblioteca Sanctorum, Roma, Istituto Giovanni XXIII della Pontificia Università Lateranense, 1966, vol. VIII, pp. 466-474.

${ }^{21}$ L. RÉAU, Iconographie de l'Art Chretien, París, Presses Universitaires de France, 1958, vol. III, pp. 846-859. Hi ha una traducció al castellà a Ediciones del Serbal, Barcelona 2000. Veure, 2a. edició, vol. V, pp. 339-343 i pp. 579-583. 
tinguessim en compte aquesta llegenda l'arquitectura del fons podria ser una al.lusió al temple de Vezelay i un dels personatges Sant Maximí, però hi ha més d'un cos mort davant la santa, la qual cosa ens fa descartar aquesta lectura per creure en el seu lloc que el retaule feia referencia a una mort o martiri col.lectiu. L'esmentada escena de la penitència a la cova o al desert, en la qual apareix la santa mig nua amb uns cabells llargs, si bé no és gaire freqüent a l'Edat Mitjana, si que comença a ser-ho a partir del Renaixement i durant el Barroc. En aquest episodi se la presenta com una pecadora arrepentida, i no pot suportar els vestits degut al gran sentiment d'amor que té per Déu, motiu pel qual se la plasma mig-nua. Cal dir que a partir de l'Edat Mitjana la santa es converteix en una amalgama de quatre persones i no tres, la quarta és Santa Maria Egipcíaca, una monja del segle VIII anomenada Magdalena que sobrevisqué a l'atac Sarraí; per tant el que s'escenificaria seria el moment posterior a l'atac quan Maria Egipcíaca és alliberada. Sembla una escena que mostra el seu patir a causa de la fe, i que recull les tradicions antiga i medieval sobre aquesta figura. Ella va viure 17 anys en una gruta $i$ morí al santuari de Saint Maximin; ha estat molt venerada pel seu arrepentiment i penitència primer a França (Provença i Borgonya), després a Itàlia (Nàpols), Anglaterra i cap el 1215 a Alemanya. De vegades —en una època més tardana i després del període renaixentista - se la mostra amb una calavera al-lusiva a les "Vanitats", un crucifix i una corona d'espines; motius propis de l'estètica barroca.

La imatge de la Magdalena semi-nua, ensenyant els pits, amb els genolls i els peus descoberts és normal, com també ho és la del seu èxtasi (levitació) a una cova, on uns àngels l'aixequen del terra set vegades cada dia i la porten al paradís, fins que un capella ho descobreix tot. Tot i que el darrer és un tema representat a partir del s. XVI, que no es pot confondre amb una assumpció de la santa. També se la pinta amb els tres pans que comprà abans d'anar al desert i que la varen alimentar durant molts anys.

El mateix autor Réau -en la versió castellana del seu llibreconsidera que s'ha donat una confusió entorn de la seva figura. Existeixen dues dones i no una: la pecadora Maria de Magdala i Maria de Betània (la segona és la germana de Marta i Llàtzer), la qual surt a la Passió de Crist, la Resurrecció de Llatzer i al peu de la Creu. Quan Crist resucita la Magdalena hi és; en aquesta escena de vegades se la representa en el moment que Crist li toca el front amb dos dits. Encara que es tracta d'un text complex, igual que el de les tres Maries, que alguns autors solventen fent-les germanes de la Verge. Els comentaris dels Apòstols no sempre coincideixen i de vegades 
consideren que primer Crist aparegué a la Magdalena. Però en cap moment es parla del martiri de la Santa al final de la seva vida. Es desconeix com va ser exactament la mort de la santa, però es creu que morí de mort natural; per tant no pot ser l'escena estudiada la de la seva mort, sinó la del moment en el que sobrevisqué a l'atac Sarraí, si bé sembla que el pintor vol explicar moltes coses sobre la santa en aquesta imatge. Hi ha la possibilitat també que l'artista volgués suggerir altres aspectes relacionats amb la seva vida, com els de la levitació i el moment anterior a la darrera comunió -episodis que vinculen alguns pintors-, i que tingueren una projecció pública i per tant transcorregueren davant d'uns personatges que la contemplaven i un àngel. Si així fos, un dels personatges seria Sant Maximí. El curiós és que la posició de la figura de genolls i amb les mans creuades com si estigués resant s'acostuma a emprar com a solució iconogràfica en les escenes de martiri de l'època. Potser l'autor s'inspirà en aquestes per realitzar la obra pels motius esmentats, i el fet de posar-la agenollada i en posició de resar serveix igualment per expresar la penitencia i l'arrepentiment, aspectes que s'han destacat en la "biografia" d'aquesta santa. Sintetitza les idees de l'arrepentiment, la fe i el patiment a causa d'aquesta. Cal recordar que a l'Edat Mitjana la Santa Magdalena de l'antiguitat clàssica es fusiona amb la Magdalena Egipcíaca, una monja de la zona de Provença i des d'allà devia arribar l'esmentada tradició a Catalunya. Sinó no s'entén perquè el pintor representà una escena tant inusual dins de la iconografía de la Santa. Alguns mantenien la creença que les seves relíquies eren al santuari de Saint Maximin i no a Borgonya (criteri que defensaven d'altres), ja que consideraven que ella morí al primer lloc esmentat i no a la Borgonya. Per tant les seves restes no podien ser al segon lloc esmentat, sinó que a la Borgonya hi havia les de Saint Cédoine. Aquesta confusió entorn d'ella permet explicar-nos el per què el cos de la figura és un xic asexuat. Així el pintor procurà resoldre una problemática que no queda clara segons la tradició ja que es desconeixen certs aspectes i no es poden demostrar. Cal dir que a finals de l'Edat Mitjana la santa es convertí en el símbol dels mercaders de perfums, pel fet que perfumà els peus de Crist amb un pot d'aromes.

Pel que fa al personatge masculí, tot i que podria ser Sant Lleïr o Sant Llop, sembla que per les característiques de la vida del primer ha de ser Sant Lleïr. Sobre el primer s'han trobat notícies a diversos autors. A Juan 
Fernando Roig, "Iconografía de los santos" $(1950)^{22}$, "Biblioteca Sanctorum" $(1966)^{23}$ i Louis Réau, "Iconografía del arte cristiano" $(1997)^{24}$, encara que no surt anomenat a Iacopo da Varazze, "Llegenda Auria" $(1976)^{25}$, llibre de referència destacat.

A la primera obra es parla d'un bisbe de Lleida que visqué entre el 540 i el 550, el qual té algunes capelles dedicades a Catalunya. Sempre se'l representa vestit de bisbe, sense atributs personals. Tot i que més proper geogràficament, no és aquest el sant representat, sinó un altre nascut a Espanya que va ser martiritzat a Roma a principis del s. IV; això ens ajuda a entendre l'arquitectura i l'escena per mitjà de la qual l'artista mostra clarament la influència renaixentista. Igualment el sant va vestit de carrer (no va amb vestit eclesiàstic) - la qual cosa fa descartar la primera opció-, a una mà aguanta la palma i porta una barretina, la qual cosa podem observar a l'escena de la taula que estudiem. El pintor la ha dibuixat a terra al costat del sant. També a "Biblioteca Sanctorum" surt esmentat el personatge del bisbe de Couserans que fou martiritzat i que visqué el segle VI a Italia. El mateix té culte al Sud de França i a Espanya, sobretot a Lleida, on se celebra la seva festa des del segle XII. El seu episcopat es desenvolupà enmig de lluites que oposaven els francs establerts des del 507 als visigots que venien d'Espanya i que volien reconquerir França. Els bisbes feien de caps militars i defensaven les ciutats. Es creu que morí el 27 d'agost del 540 i les seves restes foren trobades a finals del s. IX i custodiades en una església consagrada el 1017 per Sant Ramon bisbe de Barbastre, la qual fou convertida després en Catedral. Louis Réau completa l'explicació de l'anterior, ja que diu que nasqué a Espanya el 500, i morí el 548. Dóna també algunes notícies sobre el sant que no coincideixen exactament amb les de l'anterior autor.

En canvi de Sant Llop, tot i que fou un sant màrtir, no se'n conserven referències precises. Era un esclau que obtingué la llibertat gràcies a la seva lluita a favor de Crist, i que veneren a Russia i Espanya. Anastasi a "Epistola ad Episcopos Aegypti, 8, pg., XXV, col. 558" parla d'una llegenda que es va 171.

${ }^{22}$ J. FERRANDO RoIG, Iconografía de los santos, Barcelona, Ediciones Omega, 1950, p.

${ }^{23}$ Biblioteca Sanctorum, Roma, Istituto Giovanni XXIII della Pontificia Università Lateranense, 1966, vol. VIII, pp. 35-36.

${ }^{24}$ L. RÉAU, Iconografía del arte cristiano, Barcelona, Ediciones del Serbal, 1997, tomo 2, vol. 4, p. 246.

${ }^{25}$ I. DA VARAZZE, Llegenda Auria, Olot, s.1.e., 1976, LXXVII, 1063 p. 
difondre a Espanya i que no tots consideren que sigui verdadera, per la qual se'l va fer un màrtir d'origen local. Aquesta diu que era un esclau que feia miracles, fou tancat a la presó i condemnat a morir. Hi ha una altra versió de Sant Demetri de Tesalónica "BSS, IV, col. 556 sgg." Que coincideix força amb la d'Anastasi. Ambdós creuen que era sorprenent que es rendís culte a un esclau ${ }^{26}$.

\section{CONCLUSIONS}

Encara que només hem pogut realitzar aproximacions al tema, degut a la manca de dades documentals, i a les poques referències obtingudes en altres pintures de l'època: de Sant Lleïr no n'hem trovat cap altre representació, i de Santa Magdalena, les que hem aconseguit no mostren el mateix capítol de la vida, sinó altres ja esmentats i que són molt més coneguts. El cert és que es tracta de dues taules anònimes tardo-gòtiques molt probablement referides a aquests sants pel lloc on han estat trobades. Cal dir, que tot i que algunes escenes de sants es plasmen de manera més habitual que d'altres, el repertori iconogràfic és ampli i no se solen repetir d'una manera molt semblant les escenes i temes, si tenim en compte el conjunt d'obres que ens ha quedat.

La mort per crucifixió, a la foguera i per degollament eren freqüents pel que fa als sants màrtirs, tot i que no he trobat una descripció més acurada de com varen finalitzar la seva vida ni Santa Magdalena, ni Sant Lleïr. Jo he procurat centrar-me en escenes similars de martiri que es representaren en aquells moments, amb la finalitat d'observar les posicions del cos, de les mans, la vestimenta i altres aspectes relacionats amb el fons arquitectònic $o$ de paisatge de les taules, per comparar les solucions iconogràfiques en ambdós casos, encara que no es tracti estrictament d'un martiri que condueixi a la mort en el cas de Santa Magdalena — com ja hem esmentat-, sinó d'una barreja d'aquest amb altres conceptes i per tant d'una manera de mostrar com se salva a causa de la fe en Déu; l'artista inverteix els termes: no mor per les seves creences, sinó que són aquestes, la fe i l'ajuda de Déu les causes que la salven. Es modifica per tant el concepte clàssic de martiri, i aquest ja no

${ }^{26}$ Biblioteca Sanctorum, Roma, Istituto Giovanni XXIII. Pontificia Università Lateranense, 1967 , vol. VIII, p. 384. 
serveix per assolir una altra vida millor, sinó per viure més temps a la Terra, una idea ja més pròpia del Renaixement que de l'Edat Mitjana.

Tanmateix, tot i que no hi ha cap obra igual, o que pugui qualificar-se d'una còpia exacta, coincidim al pensar que hi ha una manera de mostrar el màrtir que es molt peculiar de l'època i que apareix lleugerament modificada a les diverses pintures. Per tant, tot i les constants formals es reafirma una creativitat. Aquest tema, sinó molt abundant, acostumava a observar-se a les pintures sobre taula. He exclòs les escenes de martiri que s'apartaven de les fòrmules iconogràfiques trobades a Les Tragines, pel fet de tractar-se de solucions diferents, com per exemple el de la representació del màrtir de peu.

És cert que els artistes s'influïen els uns als altres en les actituds dels personatges, el nombre i tipus de figures: el sant o santa, un o dos botxins, alguns personatges de la Cort, un monarca o senyor que regia, etc... són ingredients que trobem en aquest tipus de peces i també se'n presenten d'altres. Com el fet de situar les figures davant un marc arquitectònic: una muralla, una casa o bé a l'interior d'una sala amb la finalitat d'obtenir una profunditat que s'apropa a la perspectiva intuitiva; ocasionalment introdueixen darrera de tot un fons de paisatge substituint el daurat. L'ús d'elements simbòlics i identificatius: el tipus de barret, i de vestit ajuden molt a conéixer les característiques dels personatges representats (soldats, clergues, reis, ...). També els aspectes de caire moralitzant hi són expresats en aquestes pintures: la fe, la creença en Déu és mostrada com un fet lloable en el personatge pintat. Aquests ingredients i d'altres venien moltes vegades condicionats pels contractes, els quals determinaven les característiques i condicions que havia de tenir un encàrrec. D'aquí que moltes vegades l'artista no podia treballar amb una total llibertat, sinó que es trobava condicionat per la voluntat dels comitents que eren els que prioritàriament reflectien la seva tendència i gust en les obres de l'època, ja que la seva condició social i cultural superior els permetia regir en aquests camps. És més, per mitjà de les miniatures i manuscrits mantenien una proximitat amb les fonts i es servien d'aquests mitjans per projectar els seus continguts textuals i visuals en el món de l'art. En canvi, l'artista tenia una formació humanística i un nivell de coneixements inferior, havent-se d'adaptar al criteri predominant. En la major part dels casos aquest era analfabet o no comptava amb un repertori ampli de material gràfic i documental, sinó que més aviat partia de l'observació directa d'altres retaules i peces. La introducció dels gravats uns anys després li facilitarà molt aquesta tasca. 
Cal dir que a partir dels segles IX-X els sants adquiriren molta importància per la població i es transformaren en herois en nom de la fe. Aquest motiu va fer que es creessin llegendes entorn de la seva vida; sobretot procedents del poble que no coneixia ben bé els fets, ni les seves aventures o miracles; motiu pel qual els hi feien atribucions, ja que les explicacions es transmitien de boca en boca i fins el Concili de Trento no es buscà un rigor. La tasca de l'artista consistia en immortalitzar un aspecte de la vida del sant o santa, seguint la tradició local, i el representava d'acord amb el context. Aquesta versió defensada per Emile Mâle ${ }^{27}$ ens permet entendre i donar sentit als martiris estudiats, sobretot pel que fa al de Santa Magdalena. De vegades els fets no estaven ben interpretats localment i es barrejaven legendes, o bé se'ls donava a aquests personatges uns nous atributs.

També cal destacar l'influència en aquesta zona de les tradicions religioses de la Catalunya Nord, àmbit geogràfic amb el qual la Vall de Lord mantenia un comerç del drap i altres intercanvis que afavorien aquesta relació estreta entre ambdues parts. Aquest motiu facilita que en les obres s'ajuntin dos aspectes: la introducció d'una composició i forma plàstica que ja són quasi renaixentistes, i la pervivència de les tradicions religioses medievals, que fan que les escenes de la vida dels sants representats no recullin la tradició clàssica en la seva puresa, sinó la medieval procedent del món carolingi, ja que s'observen com enemics no sols els personatges del món pagà antic, sinó també els visigots en el cas de Sant Lleïr i els musulmans en el de Santa Magdalena, cosa que reflectéix l'estret llaç que hi ha en aquesta zona amb el Sud de França o Catalunya Nord. Tanmateix cal recordar que les notícies sobre santa Magdalena són molt més abundants i també la seva representació és més freqüent, cosa que no es pot dir el mateix sobre sant Lleïr.

Finalment cal fer constar que les dues peces estudiades es troben en curs de restauració a l'Escola Superior de Conservació i Restauració de Béns Mobles de la Generalitat de Catalunya al barri de la Trinitat de Barcelona.

\footnotetext{
${ }^{27}$ Es seguéis la interpretació d'aquest autor al llibre quart titulat: "Los santos y la leyenda dorada", a l'obra, El arte religioso del s. XIII en Francia. El gótico, Madrid, Ediciones Encuentro, 2001, pp. 299-368.
} 


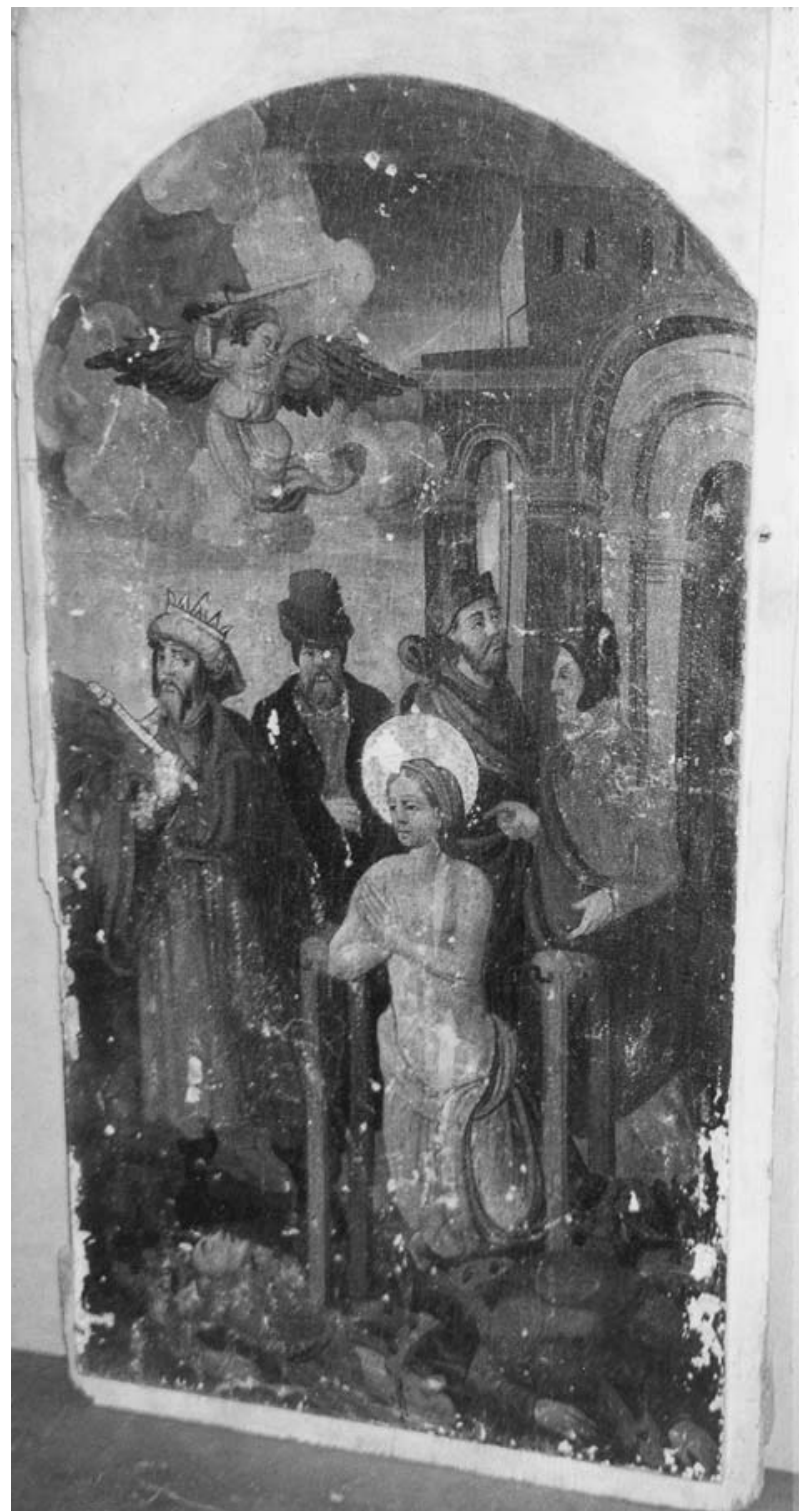

Fig. 1. Santa Magdalena. Església de Santa Magdalena de les Tragines (final s. XV-començament XVI) (Sant Llorenç de Morunys, Museu del Patronat Vall de Lord). 


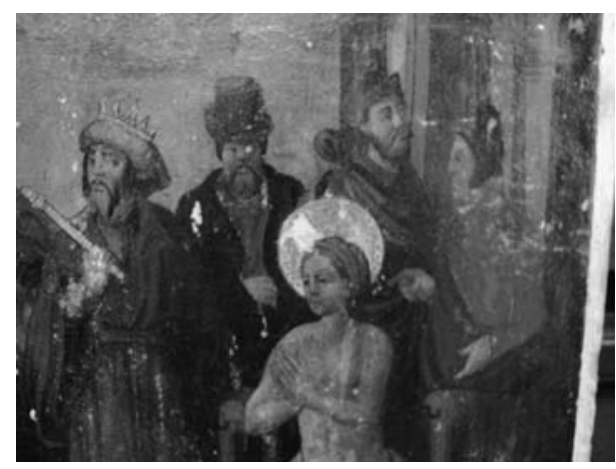

Fig. 2. Santa Magdalena (detall)

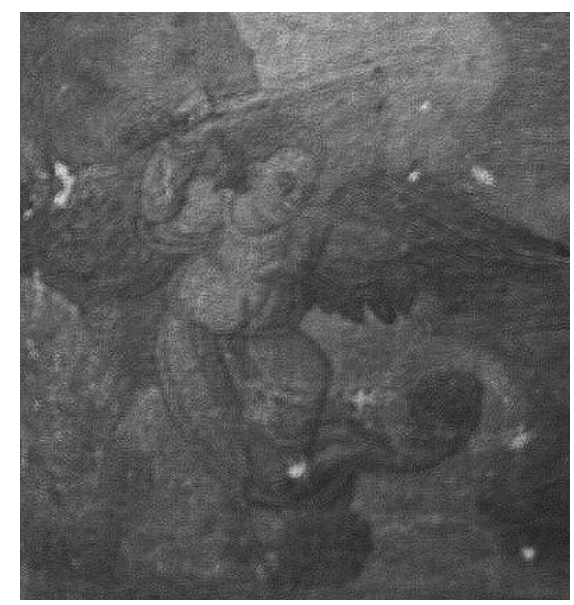

Fig. 3. Santa Magdalena (detall) 


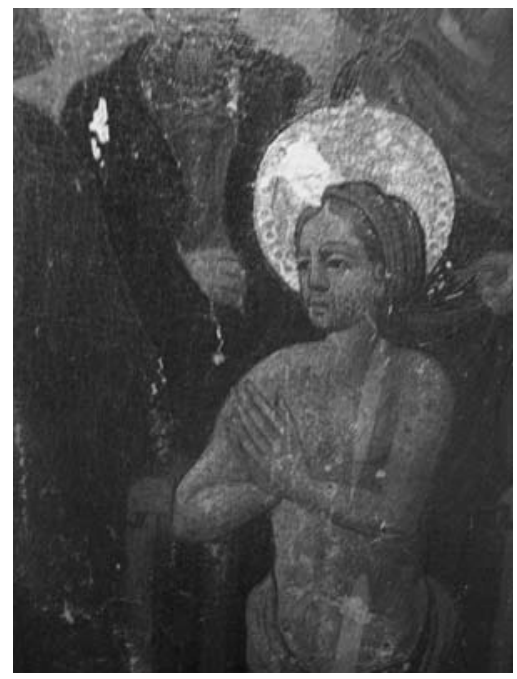

Fig. 4. Santa Magdalena (detall)

Fig. 5. Santa Magdalena (detall)

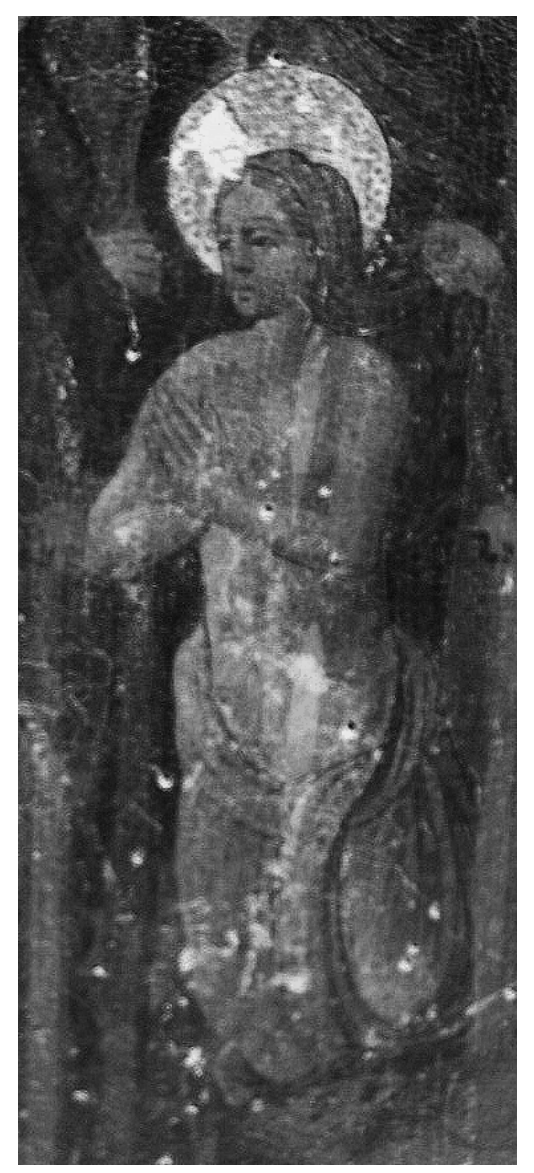




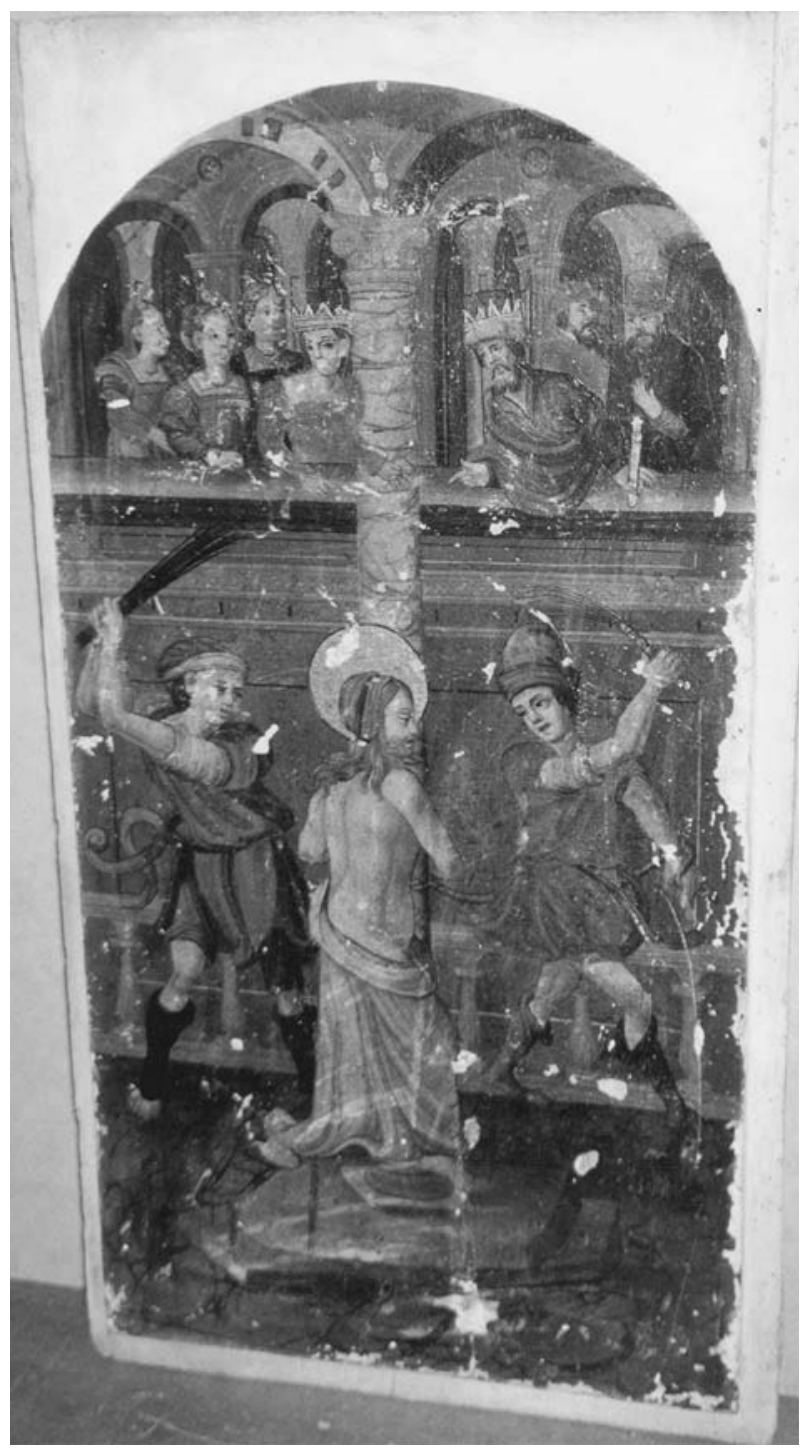

Fig. 6. Sant Lleïr. Església de Santa Magdalena de les Tragines (final s. XV-començament XVI) (Sant Llorenç de Morunys, Museu del Patronat Vall de Lord) 

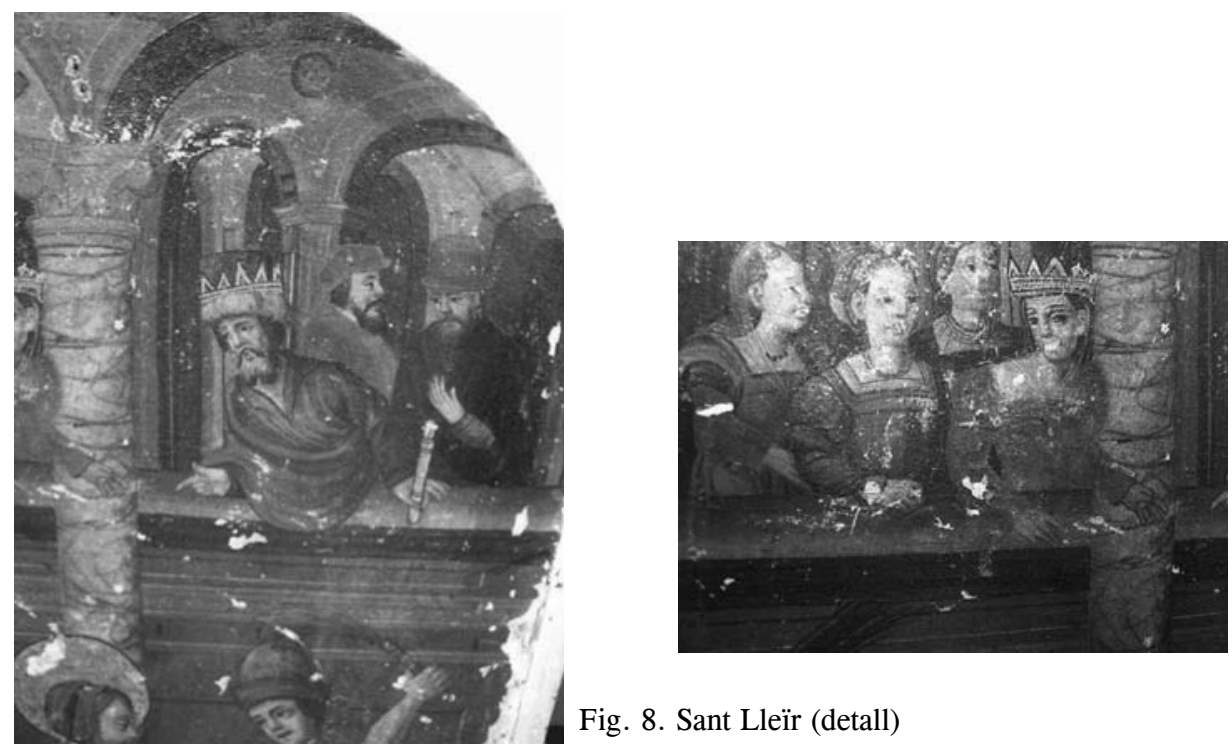

Fig. 8. Sant Lleïr (detall)

Fig. 7. Sant Lleïr (detall)

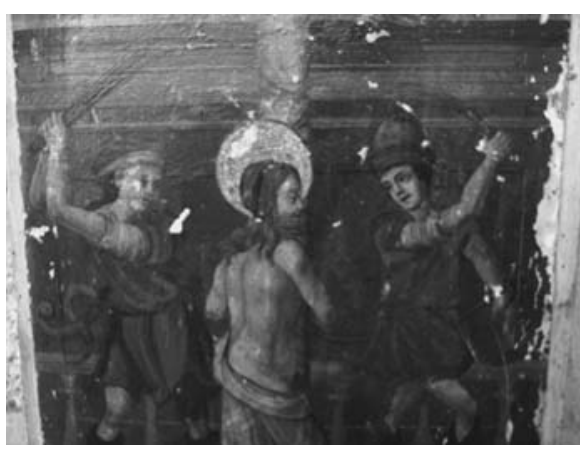

Fig. 9. Sant Lleïr (detall) 